\title{
Invited Response on: The Effect of Apocynin on Fat Graft Survival
}

\author{
Dogan Çakan ${ }^{1}[$
}

Received: 2 April 2021/Accepted: 4 April 2021/Published online: 19 April 2021

(C) Springer Science+Business Media, LLC, part of Springer Nature and International Society of Aesthetic Plastic Surgery 2021

Level of Evidence $V$ This journal requires that authors assign a level of evidence to each article. For a full description of these Evidence-Based Medicine ratings, please refer to the Table of Contents or the online Instructions to Authors www.springer.com/00266.

To the Editor,

Keskin and Cakan proved that systemic apocynin increases fat graft survival in the fat grafting model in rats, as the first in the literature[1]. This study has contributed to the literature with its simple and easy to repeat method. Different methods have been reported for fat grafting. The first technique is to place the obtained adipose tissue directly into the recipient area without any additional procedure [2] Transferring the fat graft without any procedure is not preferred today due to the necrosis, the vascularization process starts from the periphery so there is less blood supply in the center of the graft, of the fat cells[2]. Less necrosis develops and the graft has a higher survival rate in other methods such as liposuction or splitting the graft into small pieces [3]. Keskin and Çakan used apocynin on the method with the lowest chance of graft survival in their studies. In this way, they showed that they can achieve a positive effect with apocynin even on the method with the lowest graft survival rate. In addition, they stated that transferring the fat graft without trauma is among the limitations of their study.

Keskin and Çakan's study is on the examination of the positive or negative effects of apocynin on fat graft survival. Their study is the first to show the positive effects of

Dogan Çakan

drdgnckn@gmail.com

1 ENT Department Cerrahpasa Medical School, Istanbul University-Cerrahpasa, Istanbul, Turkey apocynin on fat grafting. The mechanism of this effect is the subject of a more comprehensive study.

In conclusion, this study, which shows that apokinin increases fat graft survival, is the first in the literature. The repetition of this study with larger numbers of subjects and the mechanism of the effects of apocynin on fat grafting are the subjects of future studies.

Acknowledgements This study has no financial supporters. The authors thank Professor Abdullah Tuten for reading proof.

\section{Declarations}

Conflict of interest The authors declare that they have no conflicts of interest to disclose.

Human and Animal Rights This article does not contain any studies with human participants or animals performed by any of the authors.

Informed Consent For this type of study, informed consent is not required.

\section{REFERENCES}

1. Keskin ER, Çakan D (2021) The effect of apocynin on fat graft survival. Aesthet Plast Surg. https://doi.org/10.1007/s00266-02102180-Z

2. Güney K, Tatar S, Özel B, Seymen C, Elmas Ç, Tuncer S, Çenetoğlu S (2019) The effect of minocycline on fat graft survival and apoptotic pathway. Fac Plast Surg. 35(1):96-102

3. Pu LL, Coleman SR, Cui X (2008) Autologous fat grafts harvested and refined by the Coleman technique: a comparative study. Plast Reconstr Surg. 122(3):932-937

Publisher's Note Springer Nature remains neutral with regard to jurisdictional claims in published maps and institutional affiliations. 